\title{
Cocaine exposure and children's self-regulation: indirect association via maternal harshness
}

\section{Rina D. Eiden ${ }^{1}{ }^{*}$, Pamela Schuetze ${ }^{2}$, Yvette Veira ${ }^{1}$, Elizabeth Cox ${ }^{3}$, Thomas M. Jarrett ${ }^{3}$ and Josephine M. Johns ${ }^{3}$}

1 Research Institute on Addictions, University at Buffalo, State University of New York, Buffalo, NY, USA

2 Psychology Department, Buffalo State College, State University of New York, Buffalo, NY, USA

${ }^{3}$ Department of Psychiatry, University of North Carolina, Chapel Hill, NC, USA

\section{Edited by:}

Elizabeth Mccone Byrnes, Tufts University Cummings School of Veterinary Medicine, USA

\section{Reviewed by:}

Stephen Sheinkopf, Brown University, USA

Veronica H. Accornero, University of Miami Miller School of Medicine, USA

\section{${ }^{*}$ Correspondence:}

Rina D. Eiden, Research Institute on Addictions, University at Buffalo, 1021 Main Street, Buffalo, NY 14203, USA. e-mail: eiden@ria.buffalo.edu
Objectives: This study examined the association between prenatal cocaine exposure and children's self-regulation at 3 years of child age. In addition to direct effects of prenatal cocaine exposure on children's self-regulation, we hypothesized there would be indirect associations between cocaine exposure and self-regulation via higher maternal harshness and poor autonomic regulation in infancy. Methods: The sample consisted of 216 mother-infant dyads recruited at delivery from local area hospitals (116 cocaine-exposed, 100 non-exposed). Infant autonomic regulation was measured at 7 months of age during an anger/frustration task, maternal harshness was coded from observations of mother-toddler interactions at 2 years of age, and children's self-regulation was measured at 3 years of age using several laboratory paradigms. Results: Contrary to hypotheses, there were no direct associations between maternal cocaine use during pregnancy and children's self-regulation. However, results from testing our conceptual model including the indirect effects via maternal harshness or infant parasympathetic regulation indicated that this model fit the data well, $\chi^{2}(23)=34.36, p>0.05$, Comparative Fit Index $=0.95$, RMSEA $=0.05$. Cocaine using mothers displayed higher intensity of harshness toward their toddlers during lab interactions across a variety of tasks at 2 years of age $(\beta=0.23, p<0.05)$, and higher intensity of harshness at 2 years was predictive of lower self-regulation at 3 years $(\beta=-0.36, p<0.01)$. Maternal cocaine use was also predictive of a non-adaptive increase in respiratory sinus arrhythmia (RSA) from baseline to the negative affect task, but RSA change in infancy was not predictive of self-regulation at 3 years. Conclusion: Results are supportive of animal models indicating higher aggression among cocaine treated dams, and indicate that higher maternal harshness among cocaine using mothers is predictive of child self-regulatory outcomes in the preschool period.

Keywords: cocaine exposure, self-regulation, maternal harshness, autonomic regulation

\section{INTRODUCTION}

Maternal cocaine use remains a significant problem affecting large numbers of mothers and their children (Savitz et al., 2002). Increasingly, studies have indicated that prenatal exposure to cocaine is associated with alterations in infant behavioral and physiological regulation. Because cocaine crosses the fetal bloodbrain barrier, it has the potential to directly alter neurotransmitter systems in the developing fetal brain. Cocaine is known to inhibit the re-uptake of monoamines at the presynaptic junction, leading to higher concentrations of norepinephrine, serotonin, and dopamine in the synaptic cleft and higher levels of activation in the catecholaminergic systems (Gawin and Ellinwood, 1988; Nassogne et al., 1998). Regions of the brain that are rich in monoamines are the very centers involved in regulatory activities and reactivity to stress (Tucker and Williamson, 1984; Robbins, 1997). A number of human studies have consistently reported significant associations between prenatal cocaine exposure and some aspects of the regulatory system including both behavioral (Karmel and Gardner, 1996; Bendersky and Lewis, 1998; Mayes et al., 1998) and autonomic regulation (Silvestri et al., 1991; Bard et al., 2000; Schuetze and Eiden, 2006; Schuetze et al., 2009b). Animal models also indicate that prenatal cocaine alters offspring attention and arousal regulation (Gendle et al., 2004), disrupts emotionality and social behaviors in juvenile and adult offspring (Wood et al., 1994, 1995; Johns and Noonan, 1995; Johns et al., 1998a; Wood and Spear, 1998; Overstreet et al., 2000), and increases sensitivity to environmental stressors (Sobrian et al., 1990; Spear et al., 1998). Taken together, both the human literature and studies using animal models suggest that prenatal cocaine exposure has the potential to significantly alter the regulatory system.

One physiological regulatory system that supports infant social behaviors including later self-regulation is the parasympathetic branch of the infant autonomic system. This system allows for quick changes in metabolic inputs and outputs from the heart and facilitates behaviors necessary for social exchanges. Two commonly used measures of parasympathetic regulation are vagal tone or respiratory sinus arrhythmia (RSA), a measure of variability in heart rate that occurs at the frequency of respiration or 
vagal tone during rest, and vagal reactivity indexed by change in RSA in response to challenge (Porges, 1991, 2007). In response to challenge, the vagus acts as a brake to accelerate cardiac and metabolic output and this may be indexed by a decrease in RSA (Porges, 1996, 2007; Bornstein and Suess, 2000). Change in RSA as a response to challenge reflects an ability to respond to rapidly changing environmental inputs, i.e., changes in social signals that underlie interpersonal interactions (Beauchaine, 2001) and the initiation of coping strategies to manage affective and behavioral arousal (Calkins, 1997). RSA change is associated with aspects of self-regulation such as executive control (Marcovitch et al., 2010) and externalizing behavior problems (Calkins et al., 2007), with RSA decrease or vagal withdrawal indicating more adaptive regulatory functioning. Thus, RSA change in response to challenge during infancy is likely to be a significant prospective predictor of self-regulation in later years.

There is emerging evidence that prenatal cocaine exposure may be associated with poor autonomic regulation. However, the majority of these studies have been limited to the neonatal period. For instance, studies have reported lower heart rates (Silvestri et al., 1991), greater high-frequency power as a portion of total spectral power indicating an increase in vagal activity (Mehta et al., 1993), and greater overall heart rate variability (Regalado et al., 1996, 2001) in cocaine-exposed compared to non-cocaine-exposed neonates. These studies suggest increased parasympathetic activity during rest among cocaine-exposed neonates. Beyond the neonatal period, previous results from the current study sample indicated that cocaine-exposed infants exhibited lower parasympathetic regulation during sleep at 4-8 weeks of age (Schuetze and Eiden, 2006), and an increase in RSA from rest to challenge instead of the more adaptive decrease in RSA at 7 and 13 months of infant age (Schuetze et al., 2009a,b). These altered RSA responses could therefore indicate altered parasympathetic regulation and perhaps be a predictor of altered self-regulation later in life.

As the child develops after birth, reactive forms of regulation are increasingly supplemented by effortful forms of control or self-regulation through interactions with the caregiving environment (Rothbart et al., 1990). Flavell (1977) described selfregulation as the "one of the really central and significant cognitivedevelopmental hallmarks of the early socialization period" (p. 64). Although there are numerous definitions of self-regulation, a common theme is the process of modulating behavior and affect given contextual demands (Posner and Rothbart, 2000). Although regulatory processes begin to develop in the prenatal period, regulation evolves into a complex and relatively stable self-initiated process by the preschool period (see Calkins and Fox, 2002; Campbell, 2002). Recently, two related but distinct aspects of self-regulation in the preschool to early school age period have been delineated, effortful control and internalized conduct. Effortful control has been defined as the ability to suppress inappropriate behavior and perform required or appropriate behavior in response to environmental demands. Effortful control becomes increasingly important beyond the second year of life, has considerable longitudinal stability, and predicts externalizing behavior problems at later age (Rothbart et al., 1994; Kochanska et al., 1997; Kochanska and Knaack, 2003; Eisenberg et al., 2005a). Internalization of rules of conduct has been defined as regulated or appropriate behavior in response to contextual demands even in the absence of surveillance (e.g., Kopp, 1982; Maccoby and Martin, 1983; Kochanska and Aksan, 1995). The normative change from external monitoring of child behavior to more self-regulated behavior even in the absence of close supervision is the result of developing internalization of rules of conduct.

A variety of factors may disrupt the development of selfregulation. Primary among these is the quality of parenting or caregiving. A number of parenting dimensions have been examined in the literature, and the pattern of results indicate that several different aspects of parenting prospectively predict the development of self-regulation (see Eisenberg et al., 2004; Calkins and Hill, 2007, reviews). Intrusive, hostile, punitive, and/or directive parenting styles have been uniformly associated with poor selfregulation among children, while warm, supportive parenting has been associated with more optimal self-regulation (see Eisenberg et al., 2004). One aspect of parenting that may be particularly significant among CE children is maternal hostility or harshness. Cocaine using mothers are more disengaged and passive during mother-infant interactions in the neonatal period (Gottwald and Thurman, 1994); are less flexible and engaged during feeding interactions (LaGasse et al., 2003); have lower responsiveness and enthusiasm in later infancy (Burns et al., 1991, 1997); are less emotionally engaged in the toddler period (Molitor et al., 2003); use fewer positive reinforcements and more threats of physical discipline in the toddler/preschool period (Bauman and Dougherty, 1983); display more harshness or aggression during different laboratory based interactions at 2 years of age (Eiden et al., 2011); and are more hostile and intrusive in a structured teaching situation at 3 years of age (Johnson et al., 2002). Higher maternal hostility or harshness toward the child has significant implications for the development of children's self-regulation (see Eisenberg et al., 2004, review).

A number of studies on alterations in maternal behavior as a function of cocaine use have used animal models. Treatment with a constant moderate dose of cocaine throughout gestation results in rat dams being less attentive to their pups. Behaviors that are altered in cocaine treated dams compared to saline controls are those important for the pups' survival including: nursing, licking, and touching pups, spending time with pups and preparing nests for them. These deficits in maternal care are especially prevalent during the early postpartum period (Zimmerberg and Gray, 1992; Johns et al., 1994, 1998a; Kinsley et al., 1994; Vernotica et al., 1996), have been shown to disrupt maternal care following both acute and chronic moderate cocaine doses (Vernotica et al., 1996; Johns et al., 1998a; Nelson et al., 1998; Lubin et al., 2001), and can also be found following direct administration of cocaine to brain nuclei implicated in the regulation of maternal behavior (Vernotica et al., 1999). Gestational cocaine treatment also results in non-protective or overly aggressive behavior toward an intruder. Even in the presence of a submissive home cage intruder, dams exposed to cocaine, exhibited more non-adaptive and compulsive aggressive behavior than saline controls (Heyser et al., 1992; Johns et al., 1994,1998b). Additionally, young adult mother rats that were reared by cocaine treated mothers or were gestationally exposed to cocaine, subsequently exhibited heightened aggression toward non-threatening intruders with no correlated increase in 
pup contact or care. These findings indicated an intergenerational effect in maternal aggressive behavior based on either, cocaine exposure or postnatal environment (McMurray et al., 2008).

Results from a number of studies support the association between maternal harshness and self-regulation. Mothers who display higher verbal or physical harshness toward their children use these punitive methods to control behavior. Maternal use of power oriented discipline characterized by high punitive or aggressive control and low positive affect is universally detrimental to the development of children's self-regulation (Baumrind, 1971; Maccoby and Martin, 1983; Kochanska and Knaack, 2003). The association between maternal harshness during mother-child interactions and children's self-regulation may reflect modeling of poor self-control, some aspect of temperamental risk transmission, or a combination of both.

Thus, in addition to potential direct effects of prenatal cocaine exposure on children's self-regulation, there may be two indirect pathways linking maternal cocaine use to children's self-regulation, one via the association of maternal cocaine use and higher maternal harshness, and the other via poor parasympathetic regulation in infancy. The purpose of this study was to examine a conceptual model testing these indirect associations between maternal cocaine use during pregnancy and children's self-regulation at 3 years of age. Given the association between maternal cocaine and other substance use such as cigarettes and alcohol, the model tested in this study included amount of cigaret and alcohol use during pregnancy. Boys have been found to have lower self-regulation compared to girls, and the direct and indirect associations between maternal cocaine use and self-regulation may vary as a function of child gender. Thus, we hypothesized that child gender may serve as a moderator of these associations, such that the associations between cocaine exposure and children's self-regulation may be stronger for boys compared to girls.

\section{MATERIALS AND METHODS PARTICIPANTS}

The sample consisted of 216 mother-infant dyads participating in an ongoing longitudinal study of prenatal cocaine exposure (116 cocaine-exposed or CE, 100 not cocaine-exposed or NCE). An outreach worker on the project staff recruited all participants after delivery from two local area hospitals. Mothers ranged in age from 18 to 42 years $(M=29.78$; SD $=5.46)$. The majority of mothers were African American (74\%), were receiving Temporary Assistance for Needy Families (71\%) at the time of their first laboratory visit (Years 2001-2004), and were single (60\%). Of the 216 children, 106 (49\%) were male. All families were recruited from two hospitals serving a predominantly low-income population and the two groups were matched on maternal education, maternal race/ethnicity, and infant gender. The study received approval from the children and youth institutional review board of the University at Buffalo. Informed written consent was obtained from all recruited participants. Participants were compensated for their time in the form of gift certificates, checks, and infant toys at each assessment, with the amount increasing over time. All infant assessments (birth to 2 years) were conducted at age corrected for prematurity.
Maternal and child assessments were conducted at 4-8 weeks, $7,13,24$, and 36 months of child age. By 36 months of child age, 46 children in the cocaine group and 4 children in the control group had been removed from parental care and placed in non-parental care. All assessments were conducted with the primary caregiver of the child at that time, although for ease of presentation the terms mother and maternal are used throughout the manuscript when referring to the primary caregiver. The primary caregiver was identified as the adult who had legal guardianship of the child and accompanied the child at all appointments.

\section{PROCEDURE}

All mothers were screened after delivery for initial eligibility and matching criteria. Interested and eligible mothers were given detailed information about the study and asked to sign consent forms. About 2 weeks after delivery, mothers were contacted and scheduled for their first laboratory visit, which took place at the time that their infant was approximately $4-8$ weeks old. All visits consisted of a combination of maternal interviews, observations of mother-infant interactions, and infant assessments. In the circumstance of a change in custody arrangements, the person who had legal guardianship of the child was contacted and asked to participate. Biological mothers were interviewed at the 4- to 8-week assessment in addition to the foster mother in order to obtain accurate information about prenatal substance use.

Once a family was recruited into the cocaine group, the closest matching non-cocaine group family was recruited. However, a significantly higher proportion of mothers in the non-cocaine group declined participation or withdrew before formal enrollment, resulting in a smaller number of families in the control group. Of the 4,800 women screened at delivery, 340 were eligible for participation in either group. Of these 340 women, 35\% either declined participation or were not enrolled in the study because they expressed initial interest but later withdrew, resulting in a sample of 220 mother-infant dyads. Of these 220 motherinfant dyads, 4 were excluded from analyses (two infants were later diagnosed with fetal alcohol syndrome, one was later diagnosed with shaken baby syndrome, and one infant was severely delayed), resulting in a final sample of 216 dyads. Mothers who participated were more likely to be between 18 and 25 years of age $(p<0.001)$, and were more likely to have a high school or below high school education $(p<0.001)$, compared to those who were eligible but not enrolled. Mothers who participated were also more likely to be in the cocaine group (with a participation rate of $91 \%$ among cocaine group eligibles) compared to those who were eligible but not enrolled. The majority of mothers in the cocaine group who were eligible but not enrolled in the study had children who were placed in non-maternal care. There were no other differences on any demographic variables between those who participated and those who were eligible but not enrolled or between mothers in the cocaine group who participated compared to those who did not.

\section{ASSESSMENT OF GROWTH AND RISK STATUS}

Three measures of growth were used in this study: birth weight $(\mathrm{gm})$, birth length $(\mathrm{cm})$, and head circumference $(\mathrm{cm})$. All measurements were taken by obstetrical nurses in the delivery 
room and recorded in the infant's medical chart. Research staff recorded this information from the charts after recruiting the mother-infant dyad. Medical chart review at the time of recruitment also was used to complete the obstetrical complications scale (OCS; Littman and Parmelee, 1978), a scale designed to assess the number of perinatal risk factors experienced by the infant. Higher numbers on this scale indicate lower obstetrical risk. Gestational age was calculated by dates and extracted from medical records.

\section{IDENTIFICATION OF SUBSTANCE USE}

Cocaine status was determined by a combination of maternal report, chart review, and maternal hair-analysis. Urine toxicologies were routinely conducted at the first prenatal visit on maternal urine and/or at delivery (for those mothers who tested positive prenatally, obtained prenatal care elsewhere, or did not receive any prenatal care) on infant and maternal urine by participating hospitals. Mothers were included in the cocaine group if self-reports were positive, regardless of urine toxicology or hair-sample results. Similarly, mothers who reported that they did not use cocaine but had positive urine toxicology or hair-samples were included in the cocaine group. Approximately 90\% $(n=195)$ of infants and mothers in the study had urine samples available for assay and hair-samples were collected for all participants.

Urine toxicologies consisted of standard urine screening for drug level or metabolites of cocaine, opiates, benzodiazepines, and tetrahydrocannabinol. Urine was rated positive if the quantity of drug or metabolite was $>300 \mathrm{~g} / \mathrm{ml}$. Hair-samples were collected from the mothers at the first laboratory visit and sent to the Psychemedics Corporation for Radioimmunoanalyses (RIAH). Hair-samples were screened for cocaine followed by a gas chromatography/mass spectrometry (GC/MS) confirmation for positive cocaine screens. Drugs and their metabolites are absorbed into the hair and can be extracted and measured. As hair grows at an average rate of $1 / 2$ inch per month, it can record a pattern of drug consumption related to the amount and frequency of use (see Baumgartner et al., 1989). Thus, a 2-inch length of hair could contain a record of approximately 4 months of use, and given adequate hair length (i.e., about $4-5$ inches), use per trimester may be recorded. Drugs become detectable in hair about 3-4 days after use, a time when cocaine is rendered undetectable by urinalysis. RIAH is the most well-established hair-analysis technique and has been replicated by independent laboratories across the world (see Magura et al., 1992). GC/MS confirmations of RIAH have not revealed any false positives because of testing errors (Magura et al., 1992). Special washing techniques and data pertaining to kinetics of washing were used to distinguish external contamination from intentional use. These methods have been verified by independent investigators to distinguish between passive and active exposure (see Mieczkowski and Newel, 1997).

Approximately 55\% of the mothers in the CE group had positive urine toxicologies at delivery, and $79 \%$ of the mothers in the CE group had hair-samples that tested positive for cocaine during pregnancy. There were 23 mothers in the cocaine group who did not have a positive toxicology result on any biomarker of cocaine, but all of these mothers admitted to having used cocaine in the brief self-report screening instrument administered after delivery. Mothers in the comparison group reported not having used any illicit substances other than marijuana. They also tested negative for cocaine or illicit substances other than marijuana based on urine and hair-analysis results. Additional exclusionary criteria for all mothers were (a) maternal age younger than 18 years, (b) use of illicit substances other than cocaine or marijuana, and (c) significant medical problems for the infant (e.g., genetic disorders, major perinatal complications, baby in critical care for over $48 \mathrm{~h}$ ). Of the women screened at delivery, 126 acknowledged using illicit substances other than cocaine or marijuana at the screening interview and 149 infants had major medical problems. Thus, a total of 275 women were excluded based on these two criteria.

The timeline follow-back interview (TLFB; Sobell et al., 1986) was used to assess maternal substance use during pregnancy and postnatally. Participants were provided a calendar and asked to identify events of personal interest (i.e., holidays, birthdays, vacations, etc.) as anchor points to aid recall. This method has been established as a reliable and valid method of obtaining longitudinal data on substance-use patterns, has good test-retest reliability, and is highly correlated with other intensive self-report measures (Brown et al., 1998). The TLFB yielded data about the average number of days of cocaine use per week, average number of joints smoked per week, average number of cigarettes smoked per week, and average number of standard drinks per week during pregnancy. These variables were quite skewed and were transformed using square root transformations before further analyses. Average number of joints per week during pregnancy was not associated with cocaine group status (see below), or with the mediators or outcomes examined in this study. Thus, this variable was dropped from model testing. Average number of cigarettes per week and number of standard drinks per week during pregnancy were used as predictors in model testing. Postnatal substance use was computed by taking the average of number of days used cocaine, number of cigarettes per week, number of standard drinks per week, and number of joints per week from the 4- to 8-week, 7, 13, 24 , and 36 month assessments.

\section{INFANT AUTONOMIC REGULATION}

At the 7-month assessment, the physiological assessment of reactivity and regulation was recorded during a 3-min baseline period, a 2-min puppet show, a 3-min inter-task interval and a frustration task ( 2 min) by examiners blind to infant group status. Infants were tested while seated in a high-chair. Recording of the physiological data began once the infant was observed to be in a stable, quiet, alert state. A resting state was induced by having the infant watch a 3 min segment of a neutral videotape "Baby Einstein" (see Calkins, 1997, for similar procedures for inducing rest). Although this condition was not a true baseline because infant attention was engaged, it served to keep the infant seated quietly without eliciting affect, thereby minimizing movement artifact. All physiological data were recorded continuously on-line directly into a data acquisition computer.

A five-channel Bioamp (James Long Company, Caroga Lake, NY, USA) recorded respiration and electrocardiograph (ECG) data. Disposable electrodes were triangulated on the infant's chest. A respiration bellows was placed at the bottom of the sternum (xiphoid process) to measure inspiration and expiration. 
IBI Analysis software (James Long Company, Caroga Lake, NY, USA) was used to process the HR data and to calculate RSA. HR samples, which were collected every $10 \mathrm{~ms}$, were used to calculate mean HR per 1-s period. A level detector was triggered at the peak of each R-wave. The interval between sequential R-waves was calculated to the nearest millisecond. Data files of R-wave intervals were later manually edited to remove incorrect detection of the R-wave or movement artifacts. The software computes RSA using respiration and interbeat interval (IBI) data as suggested by Grossman (1983). The difference between maximum IBI during expiration and the minimum IBI during inspiration was calculated. The difference, which is measured in seconds, is considered to be a measure of RSA, and is measured twice for each respiration cycle (once for each inspiration and once for each expiration). The time for inspirations and expirations is assigned as the midpoint for each. The time for each arrhythmia sample is assigned as the midpoint between an inspiration time and an expiration time. The software synchronizes with respiration and is, thus, relatively insensitive to arrhythmia due to tonic shifts in heart rate, thermoregulation, and baroreceptor.

Average RSA was calculated for the 3-min baseline period, for the puppet show, and for each arm restraint trial. The arm restraint paradigm is a widely used, well-validated measure of anger/frustration used to assess infant regulation and reactivity (Goldsmith and Rothbart, 1988; Stifter and Braungart, 1995). In this episode, the child was allowed to play with an attractive toy for $30 \mathrm{~s}$, until the child was engaged with the toy. The caregiver was asked to stand behind the child, place her hands on the child's forearms, move them to the child's sides, and hold them there for $30 \mathrm{~s}$, while maintaining a neutral expression. After the first trial, the caregiver was again asked to play with the child for $30 \mathrm{~s}$ followed by a second trial. The session was stopped at the caregiver's request or if the child reached a maximum distress code, defined as the child reaching the highest intensity of negative affect of a full cry. This occurred for eight infants (five NCE and three CE), who had RSA data set to missing. The child was allowed to play with the toy at the end of the two trials. Because there were no significant differences in RSA between the two trials, we created mean RSA for the two arm restraint trials. To assess autonomic regulation, we calculated a change score for RSA from baseline to arm restraint. Negative scores indicate a decrease in RSA and are reflective of more optimal parasympathetic regulation.

\section{MATERNAL HARSHNESS}

Maternal harshness was coded during specific segments of the 24-month observational assessments. These included a 10-min mother-child free play paradigm, a 10-min clean-up, 8-min structured play, 10-min eating a snack, and 5-min emotion regulation paradigm. Following previous studies (Keenan and Shaw, 1994), this allowed for coding of maternal and child harshness across varying levels of stress, from none (e.g., during free play), to moderate (clean-up), to higher levels of stress (emotion regulation paradigm). For free play, mothers were asked to spend some time with their children as they normally would at home in a room with age appropriate toys. This was followed by the clean-up paradigm. Mothers were asked to have their children clean-up the toys, with the primary responsibility for toy clean-up being the child's. During snack, mother-child dyads were presented with a choice of snacks and drinks and spent time eating, and looking at books if they finished eating before $10 \mathrm{~min}$. The structured play situation consisted of a series of goal oriented tasks (e.g., puzzles, sorting, etc.). Mothers were asked to have the child complete each task. During the 5-min emotion regulation paradigm, mother-child dyads were left in the room with no toys or activities to interest the child. Mothers were asked to sit at a table and complete questionnaires. This situation is generally stressful for both mothers and reflective of naturalistic situations where they may have competing demands on their attention (Newby and Campbell, 1999).

Harshness was coded on the basis of codes developed in previous studies (Cummings et al., 1989; Keenan and Shaw, 1994). This included physical harshness (hitting, kicking, biting, pushing) directed toward a person (e.g., to mother or examiner from child, to child from mothers); physical harshness directed toward an object (e.g., banging, throwing, pounding toys); verbal harshness that consists of cursing (use of obscene language or gestures); and verbal harshness that consists of threats (words used to attack a person or threats of harm). Event coding of each aggressive episode was triggered by the mother or the child displaying any of these behaviors. Each episode was coded for duration or length of time that episode lasted, and the highest rating of harshness during that episode ranging from $1=$ none to $4=$ highly aggressive. An overall rating of intensity of maternal and intensity of child harshness was also coded along a 4-point scale ranging from $1=$ no harshness to $4=$ severely aggressive. Average intensity of verbal harshness (average or cursing and threat) ranged from 1 to $2(M=1.374, S D=0.26)$. Average intensity of physical harshness ranged from 1 to $2.25(M=1.37, \mathrm{SD}=0.28)$. Average duration of verbal or physical harshness was $69.21 \mathrm{~s}$ $(\mathrm{SD}=96.72)$. Approximately $21 \%$ of mothers displayed no verbal harshness and $21 \%$ displayed no physical harshness. The intensity of verbal or physical harshness considered individually was low. Thus, the final variable for maternal harshness consisted of the average intensity of overall harshness across the different types of harshness, with higher scores indicating higher intensity of harshness.

Two coders blind to group status rated mother and toddler harshness. They were trained by the first author until inter-rater reliability criterion was reached (agreement of $90 \%$ or above). Subsequently inter-rater reliability was established on $20 \%$ of the tapes. Inter-rater reliability on average intensity of maternal harshness was high (intra-class correlation of 0.87 ).

\section{CHILD SELF-REGULATION AT 36 MONTHS}

The latent construct of self-regulation used in data analyses consisted of three measured indicators, two effortful control measures (snack delay and prize delay) and an observational measure of internalization of rules of conduct. The effortful control tasks were taken from a battery of tasks developed by Kochanska et al. (1996b) and Kochanska and Knaack (2003). These measures have been used extensively in developmental studies, have high internal consistency, and high construct and predictive validity (see Kochanska et al., 1996a; Zimmerberg and Gray, 1992). In the first task, snack delay, the child has to wait for the experimenter to ring 
a bell before retrieving an $\mathrm{M}$ and $\mathrm{M}$ from under a glass cup (four trials: delays of 10, 20,30, and $45 \mathrm{~s}$ ). Halfway through the delay, the experimenter lifts the bell but does not ring it. Coding ranged from 0 (eats the snack before the bell is lifted) to 4 (waits for the bell to ring before touching cup or snack). The mean score on all four trials was used as the effortful control score on this task. In the second task, prize delay, the child is asked to sit on a chair facing away from the table where the experimenter is noisily wrapping the gift. The child is asked not to peek. The experimenter leaves the room for $2 \mathrm{~min}$, asking the child not to touch the gift until she returns. Coding involves a peeking score (on a three-point scale), a latency to peek score, and latency to touch score. The scores were standardized and the average of these three standard scores was used as the composite measure for prize delay. Higher scores on both composite measures indicated higher effortful control.

Observations of child internalization were conducted according to the paradigm developed by Kochanska and her colleagues (Kochanska and Aksan, 1995; Kochanska et al., 1996a). Mothers were instructed to show the child a shelf with attractive objects when they entered the observation room and to instruct the child to not touch those objects. Mothers were told that they could repeat this prohibition and/or take whatever actions they would normally take to keep their child from touching these prohibited objects during the hour-long session that followed (consisting of free play, structured play, clean-up, reading, etc.). About an hour into the observation session in the room with the prohibited objects, the experimenter asked the mother to move to the front of the room. A screen dividing the room in half was partially closed so that the parent and the child were unable to see each other. The child was asked to stay on the side of the divider containing the prohibited objects and sort plastic cutlery while the experimenter interviewed the mother on the other side of the room.

Children's internalization of the maternal directive to not touch the objects on the prohibited shelf was assessed during the 12-min observational paradigm (Kochanska and Aksan, 1995). During the first 3 min of the internalization paradigm, the child was left alone with the cutlery task. At the end of this time, a female research assistant unfamiliar to the child came in and played with the prohibited objects with obvious enjoyment for $1 \mathrm{~min}$ and then left the room. Prior to leaving, she wound up the music box, started the music, and replaced it on the shelf. The child was left with the cutlery sorting for the next $8 \mathrm{~min}$. The child's behavior was coded for every $15 \mathrm{~s}$ interval according to the coding criteria developed by Kochanska and Aksan (1995), consisting of six-point rating scales with $0=$ playing with prohibited objects in a "wholehearted," unrestrained manner to $6=$ sorting cutlery. The final composite score for internalization was computed by taking the average rating across the intervals. Internalization was coded by two independent coders blind to group status and inter-rater reliability was computed for $15 \%$ of the sample. Inter-rater reliability for internalization was high (Intra-class correlation coefficient of 0.99). Confirmatory factor analysis was conducted on the three self-regulation measures: snack delay, prize delay, and internalization of rules. These three measures loaded on one factor reflecting high self-regulation with factor loadings of $0.66,0.44$, and 0.84 for snack delay, prize delay, and internalization of rules, respectively.

\section{DATA ANALYTIC STRATEGY}

Group differences in demographics, perinatal risk characteristics, maternal substance-use variables, and maternal and child harshness were examined first using ANOVAs or MANOVAs in order to provide descriptive data and guide selection of potential covariates. MANOVAs were used when multiple theoretically associated constructs were the dependent measures in order to control for high Type I error rate. MANOVAs were used to examine group by gender interaction on maternal and child harshness to examine the hypothesis that child gender may moderate the association between cocaine exposure and harshness. Demographic or perinatal risk variables that were associated with both the predictors and outcomes at $p<0.10$ were used as covariates in subsequent analyses. Structural equations modeling (SEM) was used to test the hypothesized model with infant autonomic regulation and maternal harshness as intervening variables between maternal substance use and child behavior problems. SEM analyses were conducted using Mplus, Version 5.2 software (Muthén and Muthén, 1998-2004) using full-information maximum likelihood estimation procedures (Arbuckle, 1996). Indirect effects were tested using the bias-corrected bootstrap method. This method has been found to provide a more accurate balance between Type 1 and Type 2 errors compared with other methods used to test indirect effects (MacKinnon et al., 2004). Five hundred bootstrap samples and the $95 \%$ bias-corrected confidence intervals (CIs) were used to test significance of indirect effects.

\section{MISSING DATA}

As expected in any longitudinal study, there were some incomplete data for some of the participants at one or more of the four assessment points included in this study. Of the 216 mother-infant dyads who completed the 4- to 8-week laboratory visit, 189 completed the 7-month visit, and 177 completed the 24-month assessment, and 165 completed the 36 -month assessment. There were no significant differences between families with complete vs. missing data at 36 months on any demographic or substance-use variable. As noted earlier, full-information maximum likelihood was used to estimate model parameters.

\section{RESULTS}

\section{DEMOGRAPHICS AND PERINATAL RISK}

Results from MANOVA with the demographic variables as the dependent measures and cocaine group status yielded a significant multivariate effect of group status, $F(4,210)=6.51, p<0.01$. Results from univariate analyses indicated that control group mothers were younger, had lower parity, and higher occupation compared to those in the cocaine group (see Table 1). Correlational analyses with these demographic variables and child self-regulation indicated no significant associations. Thus, none of the demographic variables were considered in model testing.

MANOVA with perinatal outcomes and obstetrical complications as the dependent measures yielded a significant multivariate effect of group status, $F(4,210)=12.43, p<0.01$. Univariate analyses indicated that CE infants had lower gestational age, birth weight, birth length, and cocaine using mothers had higher scores on the OCS compared to those in the control group (see Table 1). Eleven percentage of CE infants (ranged from 33 to 
Table 1 | Group differences in demographic variables, birth outcomes, and substance use.

\begin{tabular}{|c|c|c|c|c|c|c|}
\hline \multirow[t]{2}{*}{ Exposure group } & \multicolumn{2}{|c|}{ Non-cocaine } & \multicolumn{2}{|c|}{ Cocaine } & \multirow[t]{2}{*}{$F$ value } & \multirow[t]{2}{*}{ Partial $\eta^{2}$} \\
\hline & $M$ & SD & $M$ & SD & & \\
\hline \multicolumn{7}{|l|}{ DEMOGRAPHICS } \\
\hline BM age & 27.77 & 5.60 & 30.82 & 6.11 & $14.57^{* *}$ & 0.06 \\
\hline BM parity & 3.22 & 1.70 & 4.15 & 2.39 & $10.75^{* *}$ & 0.05 \\
\hline Years education & 12.02 & 1.86 & 11.59 & 1.84 & 2.92 & 0.01 \\
\hline Maternal occupation & 2.09 & 1.40 & 2.55 & 1.98 & $4.02 *$ & 0.02 \\
\hline \multicolumn{7}{|l|}{ BIRTH OUTCOMES } \\
\hline Gestational age (weeks) & 39.34 & 1.24 & 38.59 & 1.85 & $11.97^{* *}$ & 0.05 \\
\hline Birth weight (gms) & 3328.84 & 504.41 & 2916.55 & 538.31 & $33.95^{* *}$ & 0.14 \\
\hline Birth length $(\mathrm{cm})$ & 49.94 & 2.91 & 48.12 & 3.11 & $19.38 * *$ & 0.08 \\
\hline Head circumference (cm) & 33.60 & 1.39 & 33.07 & 2.10 & $4.61 *$ & 0.02 \\
\hline OCS & 100.69 & 17.43 & 86.24 & 15.18 & $42.21^{* *}$ & 0.17 \\
\hline \multicolumn{7}{|l|}{ PRENATAL SUBSTANCE USE } \\
\hline Cigarettes/week & 12.77 & 25.75 & 36.99 & 43.32 & $24.16^{* *}$ & 0.10 \\
\hline Drinks/week & 0.19 & 0.82 & 3.92 & 11.47 & $10.63^{* *}$ & 0.05 \\
\hline Joints/week & 1.45 & 7.32 & 1.27 & 4.15 & 0.05 & 0.00 \\
\hline Days cocaine/week & 0 & 0 & 0.94 & 1.58 & $35.42^{* *}$ & 0.14 \\
\hline \multicolumn{7}{|l|}{ POSTNATAL SUBSTANCE USE } \\
\hline Cigarettes/week & 22.75 & 37.66 & 45.29 & 48.51 & 13.38 & 0.06 \\
\hline Drinks/week & 20.65 & 22.89 & 18.13 & 26.46 & 0.50 & 0.00 \\
\hline Joints/week & 6.97 & 22.26 & 6.72 & 14.63 & 0.008 & 0.00 \\
\hline Days cocaine/week & 0 & 0 & 0.25 & 0.84 & 7.00 & 0.03 \\
\hline Intensity of maternal aggression & 1.63 & 1.09 & 2.09 & 1.34 & $5.90 * *$ & 0.03 \\
\hline Baseline RSA & 0.03 & 0.02 & 0.02 & 0.01 & $9.29 * *$ & 0.06 \\
\hline RSA change & -0.01 & 0.02 & 0.01 & 0.03 & $17.85^{* *}$ & 0.11 \\
\hline EC: snack delay & 0.02 & 1.02 & -0.02 & 0.98 & 0.06 & 0.00 \\
\hline EC: prize delay & -0.02 & 0.99 & 0.02 & 1.01 & 0.06 & 0.00 \\
\hline Internalization of rules & 0.04 & 0.98 & -0.03 & 1.02 & 0.23 & 0.002 \\
\hline
\end{tabular}

${ }^{*} p<0.05{ }^{*} p<0.01$. BM, biological mother; OCS, obstetrical complications scale score, high scores are more optimal; EC, effortful control. Postnatal substance-use data are the average of substance use across all postnatal time points from 1 to 36 months.

41 weeks) and $3 \%$ of the control group infants (ranged from 36 to 42 weeks) were preterm ( $<37$ weeks gestational age). CE infants were significantly more likely to have been preterm than control infants, Pearson chi-square $=7.76, p<0.01$. All testing was conducted after age correction for prematurity. Infants ranged from 1531 to 5072 grams at birth $(M=3142.01, \mathrm{SD}=567.33)$. When these analyses were repeated after using gestational age as covariate, the differences in birth weight and length remained significant $(p<0.01)$. However, there were no significant associations between any of the perinatal risk variables and the child self-regulation variables. MANOVA with child sex as the independent variable and the three self-regulation variables as the dependent measures indicated a significant multivariate effect of child gender, $F(3,161)=3.53, p<0.01$. Univariate analyses indicated that boys had lower scores on prize delay compared to girls $(M=-0.22$ and $0.23, \mathrm{SD}=0.78$ and 1.14$)$, and on internalization of maternal rules $(M=3.84$ and $4.38, S D=1.46$ and 1.55$)$. Thus, child gender was included in model testing as a covariate in the testing of the overall model, followed by multiple group analyses to examine if there were gender differences in the pattern of associations.

\section{MATERNAL SUBSTANCE USE AND OTHER VARIABLES}

Results from MANOVA with prenatal substance-use variables as the dependent measures and group status as the independent variable yielded a significant multivariate effect of group status, $F(4,211)=11.46, p<0.001$. As expected, mothers in the cocaine group were heavier users of cigarettes, alcohol, and cocaine during pregnancy (see Table 1). There was no group difference in marijuana use. These results remained unchanged when the 50 foster care mothers were excluded from the analyses. MANOVA with foster care status as the independent variable and the three child self-regulation variables as the dependent variables indicated a significant multivariate effect of foster care status on child selfregulation, $F(3,161)=2.78, p<0.05$. Univariate analyses indicated that children in foster care had higher scores on prize delay indicating higher effortful control on this measure $(M=-0.10$ and $0.48, \mathrm{SD}=0.91$ and 1.26 ). There were no significant differences between biological care vs. foster care on maternal or child aggression for the sample as a whole. However, foster care mothers of cocaine-exposed children displayed lower intensity of harshness $(M=1.45$ vs. $2.28, \mathrm{SD}=1.37$ and 1.26$)$. Thus, foster care status was used as a covariate in model testing. 
GROUP DIFFERENCES IN SELF-REGULATION, MATERNAL HARSHNESS, AND RSA CHANGE

MANOVA with cocaine group status as the independent variable and child self-regulation variables at 3 years as the dependent variables indicated no significant multivariate effect of group status on self-regulation. Because the majority of children in foster care were in the cocaine group, CE children in foster care were compared with CE children in maternal care and NCE children in maternal care. Results from ANOVA indicated a significant effect of cocaine and foster care status on prize delay, $F(2,162)=5.82$, $p<0.01$. Post hoc tests indicated that cocaine-exposed children in foster care had higher effortful control scores on prize delay $(M=0.55, \mathrm{SD}=1.28)$ compared to cocaine-exposed children in maternal care $(M=-0.24, \mathrm{SD}=0.74)$ or control group children $(M=-0.01, \mathrm{SD}=1.01)$. There were no group differences on snack delay or internalization.

ANOVA with cocaine group status as the independent variable and intensity of maternal harshness as the dependent variable indicated a significant effect of cocaine group status. As indicated in Table 1, cocaine using mothers displayed higher intensity of harshness toward their children during interactions compared to control group mothers. ANOVA with cocaine group status as the independent variable and RSA variables at 7 months as the dependent variables indicated a significant effect of group status, with CE infants displaying lower baseline RSA and on average a nonadaptive increase in RSA from baseline to negative affect task while infants in the control group displayed an adaptive decrease in RSA from baseline to negative affect task (see Table 1). These results remained unchanged with other maternal substance-use variables as covariates. There were no significant associations between these variables and maternal postnatal alcohol, cigaret, marijuana, or cocaine use. Baseline RSA was not associated with any other variable in the model and results from model testing did not change with or without baseline RSA. Thus, baseline RSA was not included in the final model.

\section{MODEL TESTING}

Correlations among variables in the model are depicted in Table 2. At the bivariate level, cocaine group status was associated with higher maternal harshness and with an increase in RSA from baseline to arm restraint, but not with any of the child selfregulation measures. Intensity of maternal harshness was associated with lower effortful control (prize delay and snack delay) and with lower internalization of maternal rules.

The hypothesized model tested included maternal harshness and infant autonomic regulation as potential mediators or intervening variables between maternal substance use during pregnancy and child self-regulation. The model also included the covariance between maternal harshness and infant RSA change. Foster care status and child gender were used as covariates in the model. Goodness of fit indices indicated that this hypothesized model fit the data well $\left(\chi^{2}(23)=34.51, p=0.06\right.$, comparative fit index $=0.95$, root mean square error of approximation $=0.05$ $(0.00,0.08)$. This indirect effects model was contrasted with a model that included a direct path from maternal cocaine use to child self-regulation. Results indicated that the addition of this direct path did not improve the fit of the model, $\Delta \chi^{2}(1)=0.26$, $p=$ NS. Thus, the final model displayed in Figure 1 did not include this direct path. The structural paths indicated that mothers in the cocaine group displayed higher harshness during interactions with their 2 year olds, and higher maternal harshness toward the child at 2 years was associated with lower child self-regulation at 3 years. Although prenatal cocaine exposure was associated with poor autonomic regulation in infancy, autonomic regulation was not associated with self-regulation at 3 years. Foster care mothers displayed lower harshness toward their children.

Our model included hypotheses about several indirect effects. The association between maternal cocaine use and child selfregulation via higher maternal harshness was statistically significant $(\mathrm{B}=-0.15,95 \% \mathrm{CI}:-0.285,-0.05)$, but the indirect association via autonomic regulation during infancy was non-significant.

\section{MODERATION BY CHILD GENDER}

We examined moderation by child gender using multiple group analyses in SEM. We first examined fit indices for a fully unconstrained model for boys and girls and compared this unconstrained model with a fully constrained model. These two nested models were not significantly different from each other, $\Delta \chi^{2}(11$,

Table 2 | Correlations among variables included in model testing.

\begin{tabular}{|c|c|c|c|c|c|c|c|c|c|c|}
\hline & & 1 & 2 & 3 & 4 & 5 & 6 & 7 & 8 & 9 \\
\hline 1. & Foster care status ( $0=$ none) & & & & & & & & & \\
\hline 2. & Cocaine group status ( $0=$ control) & 0.42 & & & & & & & & \\
\hline 3. & Average \#cigs/week & 0.22 & 0.32 & & & & & & & \\
\hline 4. & Average \#drinks/week & 0.07 & 0.21 & 0.34 & & & & & & \\
\hline 5. & Intensity of maternal aggression & -0.14 & 0.18 & 0.15 & 0.13 & & & & & \\
\hline 6. & RSA change & 0.17 & 0.24 & 0.07 & 0.03 & 0.17 & & & & \\
\hline 7. & Child gender & 0.03 & 0.02 & -0.08 & -0.15 & -0.25 & -0.06 & & & \\
\hline 8. & Snack delay & 0.01 & -0.02 & 0.02 & 0.01 & -0.28 & -0.05 & 0.04 & & \\
\hline 9. & Prize delay & 0.23 & 0.02 & 0.02 & -0.11 & -0.26 & 0.00 & 0.22 & 0.27 & \\
\hline 10. & Internalization of rules & 0.06 & -0.04 & -0.02 & -0.11 & -0.32 & -0.15 & 0.19 & 0.56 & 0.36 \\
\hline
\end{tabular}

Correlations that are significant at $p<0.05$ are in bold. 


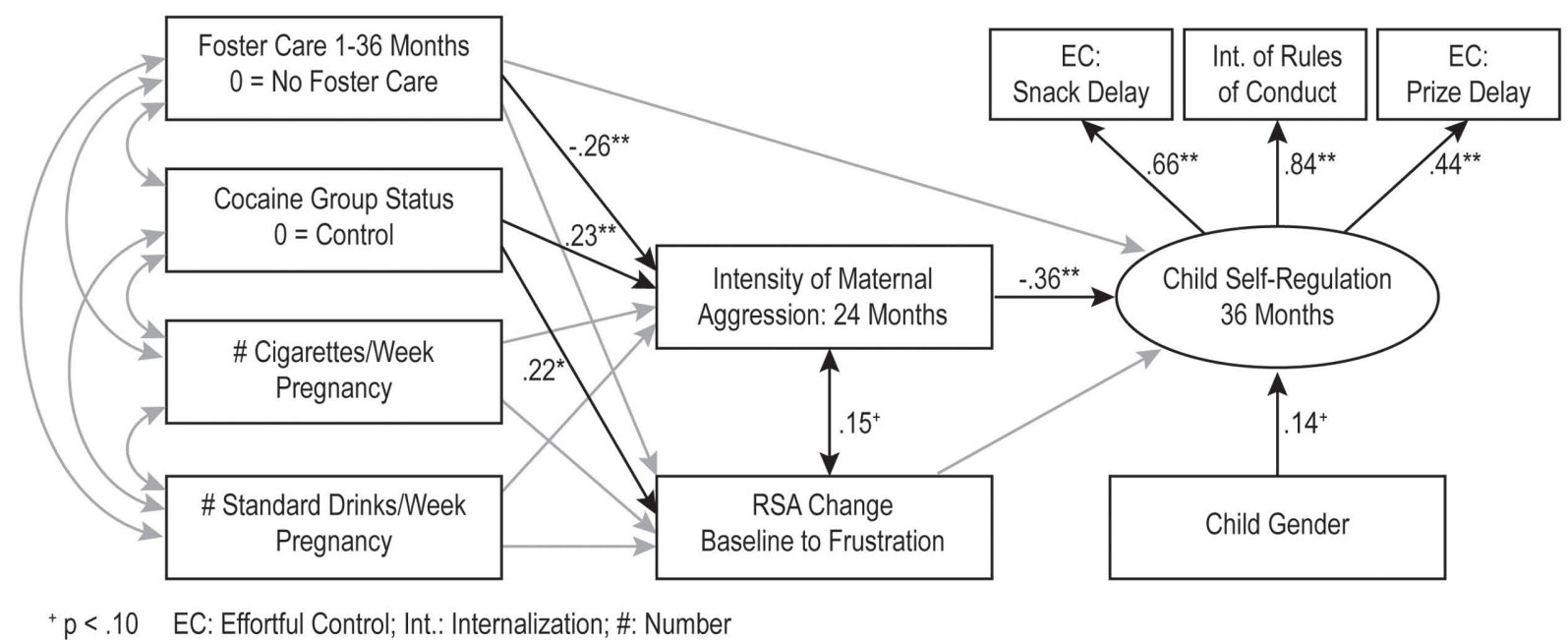

FIGURE $1 \mid{ }^{*} \boldsymbol{p}<\mathbf{0 . 0 5} ;{ }^{* *} \boldsymbol{p}<\mathbf{0 . 0 1}$. The indirect effects model $(\boldsymbol{n}=\mathbf{2 1 6})$. The numbers represent standardized path coefficients. Non-significant paths included in the model are in gray. The covariances between the exogenous variables are depicted in Table $\mathbf{2}$. The error terms for the measured indicators are not depicted in the figure.

$N=216)=7.57, p>0.05$. Thus, the pattern of associations among variables did not vary for boys and girls.

\section{DISCUSSION}

The major purpose of this study was to test a conceptual model examining potential direct and indirect associations between prenatal cocaine exposure and child self-regulation via maternal harshness and infant autonomic regulation. Results were supportive of an indirect effects model, with maternal cocaine use predicting higher maternal harshness during mother-toddler interactions at 2 years of age. Higher maternal harshness in turn was associated with lower child self-regulation at 3 years.

Contrary to expectations, results were not supportive of a direct association between prenatal cocaine exposure and child selfregulation. Few studies have examined aspects of self-regulation such as effortful control and internalization of rules among CE compared to demographically similar NCE preschoolers. Results with regard to other aspects of self-regulation have been fairly mixed. A number of studies have reported no direct associations between CE and other aspects of self-regulation (Bennett et al., 2002; Accornero et al., 2006; Warner et al., 2006; Sheinkopf et al., 2007; Yumoto et al., 2008; Bagner et al., 2009; Chaplin et al., 2009). However, others have reported poorer performance on an inhibitory control task at 5 years of age (Bendersky et al., 2003), poorer Stroop interference scores (Rose-Jacobs et al., 2009), and more externalizing behavior problems (Bada et al., 2007; Richardson et al., 2009) for CE compared to NCE children. The studies reporting no direct associations do however indicate that among substance exposed samples, factors other than cocaine exposure that are particularly prevalent in substance exposed samples may predict aspects of self-regulation.

Thus, the second goal was to test a conceptual model hypothesizing potential indirect effects between prenatal cocaine exposure and child self-regulation via higher maternal harshness and poor autonomic regulation in infancy. Results indicated that there was a significant indirect association between cocaine exposure and selfregulation via maternal harshness, but not via poor autonomic regulation in infancy. Results are supportive of previous studies indicating that harsh parental discipline is a significant predictor of child behavior problems among CE children (Bennett et al., 2002). The results are also similar to those obtained by Yumoto et al. (2008) reporting that for behavioral outcomes such as aggression and delinquency, emotional responsiveness of the primary caregiver and the emotional climate of the home were the most important predictors. Results are also supportive of the larger literature on the association between harsh parenting and poor child outcomes such as behavior problems, aggression, and emotion regulation (Chang et al., 2003; Callahan et al., 2011; Erath et al., 2011), although several studies highlight associations moderated by child reactivity (e.g., Erath et al., 2011) or neighborhood disadvantage (e.g., Callahan et al., 2011). Potential moderators of these associations among cocaine-exposed children may be a fruitful direction for further research. It is possible that the association between cocaine exposure and child self-regulation via maternal harshness is particularly salient for children with high temperamental risk.

In addition to human studies, animal models of cocaine induced maternal neglect and aggression mirror these results. Gestational cocaine treatment in rodents result in overtly aggressive behavior toward an intruder (Heyser et al., 1992; Johns et al., 1994, 1998b). Moreover, subsequent disruption in maternal care and increased aggression can be "transmitted" to next generation offspring either through prenatal exposure to cocaine or through the rearing experience when reared by a cocaine treated dam (Johns et al., 2005; McMurray et al., 2008).

The result that CE children in foster care had the highest effortful control scores on snack delay is contrary to previous reports that $\mathrm{CE}$ children in foster care were rated by their caregivers as having the highest rates of behavior problems (Linares et al., 
2006). However, the results are similar to that reported by Brown et al. (2004) indicating that CE children in foster care experienced more optimal caregiving environments and were rated by their caregivers as having fewer behavior problems at 2 years of age compared to CE children by biological mothers. These mixed findings may be a function of variables such as differences in quality of foster care, kin vs. non-kin care, duration in foster care, or number of foster care placements. We did not have sufficient sample size of children in foster care to explore these differences systematically. It may be beneficial for future studies to examine these issues using pooled samples across different studies of prenatal cocaine exposure.

Cross fostering studies in rodents not only support that prenatal cocaine exposure disrupts offspring behavioral development but also sheds light on how vital the early rearing environment is to offspring behavioral development. Healthy non-drug exposed rodent pups reared by gestational cocaine treated rodent dams show atypical patterns of maternal behavioral and aggression in adulthood (Johns et al., 2005; McMurray et al., 2008), supporting the long lasting behavioral effects altered maternal care alone can have on offspring development. Recent data also indicates early problems in infant physiological regulation in cocaine-exposed offspring which may be related to maternal response. Taken together with the results from the present study, this set of findings emphasize that the association between maternal cocaine use and poor maternal behavior has long-term implications for child development.

Unlike maternal harshness, autonomic regulation in infancy was not predictive of self-regulation at preschool age. Although studies examining associations between autonomic regulation and the aspects of self-regulation measured in this study are few in number, poor autonomic regulation has been associated with other aspects of self-regulation such as executive control (Mezzacappa et al., 1998), behavior problems (Porges et al., 1996; El-Sheikh, 2005), and executive function tasks (Marcovitch et al., 2010). With a few exceptions (e.g., Porges et al., 1996), the majority of these findings are based on cross-sectional designs. Thus, the lack of association between autonomic and self-regulation in this study may be a function of the timing of measurement, since autonomic regulation was measured in early infancy, while selfregulation was assessed at 3 years of age. Concurrent autonomic measures or those closer in time to the preschool age may have been more predictive of self-regulation. In one of the few studies of autonomic regulation among CE children predicting adaptive outcomes, Sheinkopf et al. (2007) reported that in the context of high risk including prenatal exposure, children with consistently lower RSA at 1 and 36 months during attention tasks exhibited more adaptive behaviors at 36 months. In contrast, the results of the current study were limited to autonomic regulation at one point in time during infancy and we did not examine moderation by infant autonomic regulation. Thus, it is possible that the association between cocaine exposure and self-regulation via maternal behavior may be particularly robust among children at higher physiological risk.

Contrary to expectations, gender did not moderate the association between cocaine exposure and self-regulation or the pattern of indirect associations via maternal harshness or autonomic regulation. These results are not supportive of studies indicating that the effects of prenatal cocaine exposure on aspects of self-regulation were particularly salient for boys (e.g., Dennis et al., 2006). Previous studies reporting interactive associations between gender and prenatal substance exposure variables have been with elementary school aged children (Delaney-Black et al., 2004; Bailey et al., 2005), and using teacher reports of behavior problems. It is possible that the demand of the school context leads to higher variability in aspects of self-regulation such as child behavior problems. Similarly, postnatal substance use was not associated with self-regulation or with parenting. One explanation for these results may be that a large proportion of cocaine-exposed children were placed in foster care, resulting in a smaller number of caregivers who continued to use cocaine in the postnatal period.

The results from this study suggest several directions for future research. With regard to animal models, together, the effects of prenatal drug exposure and a more neglectful rearing environment result in the most negative effects on offspring social maternal behavior as adults (Johns et al., 2007). Differential alterations in juvenile offspring social behavior have also been observed following manipulation of the rearing conditions of the CE offspring. Being grouped vs. singly housed after weaning differentially alters social investigation of an unfamiliar juvenile pup in CE offspring (Estelles et al., 2005) as does being raised in an enriched environment (Neugebauer et al., 2004). Testing whether exposure to high levels of maternal aggression disrupts the social behavior of CE rats more than isolate housing or an impoverished environment could further elucidate the salient factors in the rearing environment that lead to deficits in the social behavior of CE offspring. Altered early rearing environment has been shown to result in sex differences in juvenile and adult behavior with these differences being greater in males than females ( $\mathrm{Li}$ et al., 2008). However studies exploring sex differences and offspring behavioral outcomes correlated to altered maternal care is sparse and an area of research that needs more attention. In addition to potential sex differences, the role of foster care status in predicting self-regulatory outcome is an important area of inquiry in the human literature. Individual studies are often hampered by restricted sample size for investigating differences related to exposure status and foster care status. Perhaps pooling data from several studies with similar measures would lead to greater statistical power to investigate if foster care status moderates the effect of prenatal exposure on self-regulation.

This study has several limitations. First, accurate assessment of substance use both prenatally and postnatally is difficult. Pregnant and postpartum women are often hesitant to divulge substanceuse information, particularly illicit substances such as cocaine. One strength of this study is the use of multiple methods to ascertain prenatal substance use which partially mitigated this limitation even though the urine toxicology information was abstracted from medical records. A second important caveat of this study is that self-regulation was measured in the laboratory context and was limited to two measures of effortful control and observations of internalization. On the one hand, it is possible that the generalizability of these laboratory based measures is limited to this context. On the other hand, these are objective, observation based measures of self-regulation and do not have the method biases associated with maternal report measures of self-regulation. Further, these aspects of self-regulation in the preschool period are 
associated with disruptive behaviors in later childhood in low risk as well as high risk samples (e.g., Eisenberg et al., 2005b; Eiden et al., 2007).

In spite of these limitations, the study fills an important gap in the literature on maternal cocaine use in the examination of effortful control and internalization. An additional strength is the consideration of multiple mediators that included both maternal behavior and infant autonomic regulation. The results highlight the role of maternal harshness as a significant mediator of the association between maternal cocaine use and child self-regulation in the preschool years.

\section{ACKNOWLEDGMENTS}

The authors thank the families who participated in this study and the research staff responsible for data collection. Special thanks to

\section{REFERENCES}

Accornero, V. H., Anthony, J. C., Morrow, C. E., Xue, L., and Bandstra, E. S. (2006). Prenatal cocaine exposure: an examination of childhood externalizing and internalizing behavior problems at age 7 years. Epidemiol. Psichiatr. Soc. 15, 20-29.

Arbuckle, J. L. (1996). "Full information estimation in the presence of incomplete data," in Advanced Structural Equation Modeling: Issues and Techniques, eds G. A. Marcoulides and R. E. Schumacker (Mahwah, NJ: Lawrence Erlbaum Associates), 243-277.

Bada, H. S., Das, A., Bauer, C. R., Shankaran, S., Lester, B., LaGasse, L., Hammond, J., Wright, L. L., and Higgins, R. (2007). Impact of prenatal cocaine exposure on child behavior problems through school age. Pediatrics 119, 348-359.

Bagner, D. M., Sheinkopf, S. J., MillerLoncar, C., LaGasse, L. L., Lester, B. M., Liu, J., Bauer, C. R., Shankaran, S., Bada, H., and Das, A. (2009). The effect of parenting stress on child behavior problems in high-risk children with prenatal drug exposure. Child Psychiatry Hum. Dev. 40, 73-84.

Bailey, B. N., Sood, B. G., Sokol, R. J., Ager, J., Janisse, J., Hannigan, J. H., Covington, C., and DelaneyBlack, V. (2005). Gender and alcohol moderate prenatal cocaine effects on teacher-report of child behavior. Neurotoxicol. Teratol. 27, 181-189.

Bard, K. A., Coles, C. D., Platzman, K. A., and Lynch, M. (2000). The effects of prenatal drug exposure, term status, and caregiving on arousal and arousal modulation in 8-weekold infants. Dev. Psychobiol. 36, 194-212.
Bauman, P. S., and Dougherty, F. E. (1983). Drug-addicted mothers' parenting and their children's development. Int. J. Addict. 18, 291-302.

Baumgartner, W. A., Hill, V. A., and Blahd, W. H. (1989). Hair analysis for drugs of abuse. J. Forensic Sci. 34, 1433-1453.

Baumrind, D. (1971). Current patterns of parental authority. Dev. Psychol.4, 1-103.

Beauchaine, T. (2001). Vagal tone, development, and Gray's motivational theory: toward an integrated model of autonomic nervous system functioning in psychopathology. Dev. Psychopathol. 13, 183-214.

Bendersky, M., Gambini, G., Lastella, A., Bennett, D. S., and Lewis, M. (2003). Inhibitory motor control at five years as a function of prenatal cocaine exposure. J. Dev. Behav. Pediatr. 24, 345-351.

Bendersky, M., and Lewis, M. (1998). Prenatal cocaine exposure and impulse control at two years. Ann. N. Y. Acad. Sci. 846, 365-367.

Bennett, D. S., Bendersky, M., and Lewis, M. (2002). Children's intellectual and emotional-behavioral adjustment at 4 years as a function of cocaine exposure, maternal characteristics, and environmental risk. Dev. Psychol. 38, 648-658.

Bornstein, M. H., and Suess, P. E. (2000). Child and mother cardiac vagal tone: continuity, stability, and concordance across the first 5 years. Dev. Psychol. 36, 54-65.

Brown, J. V., Bakeman, R., Claire, D. C., Platzman, K. A., and Lynch, M. E. (2004). Prenatal cocaine exposure: a comparison of 2-year-old children in parental and nonparental care. Child Dev. 75, 1282-1295.

Brown, R. A., Burgess, E. S., Sales, S. D., Whiteley, J. A., Evans, D. M.,

Dr. Claire Coles for collaboration on the larger study, Dr. Amol Lele for collaboration on data collection at Women and Children's Hospital of Buffalo, and Dr. Michael Ray for his collaboration on data collection at Sisters of Charity Hospital of Buffalo. The work described was supported by Award Number R01DA013190 from the National Institute on Drug Abuse. Josephine M. Johns was supported by Award Number P01DA022446 from the National Institute on Drug Abuse. Elizabeth Cox was supported while working on this project by a award number 1F31 DA030060 from the National Institute on Drug Abuse as a pre-doctoral trainee. Thomas M. Jarrett was supported while working on this project by Award Number TLRR025745 from the National Center for Research Resources as a pre-doctoral trainee. The content is solely the responsibility of the authors and does not necessarily represent the official views of the National Institute on Drug Abuse or the National Institutes of Health.

and Miller, I. W. (1998). Reliability and validity of a smoking timeline follow-back interview. Psychol. Addict. Behav. 12, 101-112.

Burns, K. A., Chethik, L., Burns, W. J., and Clark, R. (1997). The early relationship of drug abusing mothers and their infants: an assessment at eight to twelve months of age. J. Clin. Psychol. 53, 279-287.

Burns, K., Chethik, L., Burns, W. J., and Clark, R. (1991). Dyadic disturbances in cocaine-abusing mothers and their infants. J. Clin. Psychol. 47, 316-319.

Calkins, S. D. (1997). Cardiac vagal tone indices of temperamental reactivity and behavioral regulation in young children. Dev. Psychobiol. 31, 125-135.

Calkins, S. D., and Fox, N. (2002). Self-regulatory processes in early personality development: a multilevel approach to the study of childhood social withdrawal and aggression. Dev. Psychopathol. 14, 477-498.

Calkins, S. D., Graziano, P. A., and Keane, S. P. (2007). Cardiac vagal regulation differentiates among children at risk for behavior problems. Biol. Psychol. 74, 144-153.

Calkins, S. D., and Hill, A. (2007) "Caregiver influences on emerging emotion regulation: biological and environmental transactions in early development," in Handbook of Emotion Regulation, ed. J. J. Gross (New York, NY: Gilford Press), 229-248.

Callahan, K. L., Scaramella, L. V., Laird, R. D., Sohr-Preston, S., Kristin, L., Callahan, L., and Laura, V. (2011). Neighborhood disadvantage as a moderator of the association between harsh parenting and toddler-aged children's internalizing and externalizing problems. J. Fam. Psychol. 25, 68-76.

Campbell, S. B. (2002). Behavior Problems in Preschool Children: Clinical and Developmental Issues, 2nd Edn. New York: Guilford Press.

Chang, L., Schwartz, D., Dodge, K. A., and McBride-Chang, C. (2003). Harsh parenting in relation to child emotion regulation and aggression. J. Fam. Psychol. 17, 598-606.

Chaplin, T. M., Fahy, T., Sinha, R., and Mayes, L. C. (2009). Emotional arousal in cocaine exposed toddlers: prediction of behavior problems. Neurotoxicol. Teratol. 31, 275-282.

Cummings, J. S., Pellegrini, D. S., Notarius, C. I., and Cummings, E. M. (1989). Children's responses to angry adult behavior as a function of marital distress and history of interparent hostility. Child Dev. 60 , 1035-1043.

Delaney-Black, V., Covington, C., Nordstrom, B., Ager, J., Janisse, J., Hannigan, J. H., Chiodo, L., and Sokol, R. J. (2004). Prenatal cocaine: quantity of exposure and gender moderation. J. Dev. Behav. Pediatr. 25, 254-263.

Dennis, T., Bendersky, M., Ramsay, D. S., and Lewis, M. (2006). Reactivity and regulation in children prenatally exposed to cocaine. Dev. Psychol. 42, 688-697.

Eiden, R. D., Edwards, E. P., and Leonard, K. E. (2007). A conceptual model for the development of externalizing behavior problems among kindergarten children of alcoholic families: role of parenting and children's self-regulation. Dev. Psychol. 43, 1187-1201.

Eiden, R. D., Schuetze, P., Colder, C. R., and Veira, Y. (2011). Maternal cocaine use and mother-toddler aggression. Neurotoxicol. Teratol. doi: 10.1016/j.ntt.2011.03.001 
Eisenberg, N., Sadovsky, A., Spinrad, T. L., Fabes, R. A., Losoya, S. H., Valiente, C., Reiser, M., Cumberland, A., and Shepard, S. A. (2005a). The relations of problem behavior status to children's negative emotionality, effortful control, and impulsivity: concurrent relations and prediction of change. Dev. Psychol. 41, 193-211.

Eisenberg, N., Smith, C. L., Sadovsky, A., and Sprinrad, T. L. (2004). "Effortful control: relations with emotion regulation, adjustment, and socialization in childhood," in Handbook of Self-regulation: Research, Theory and Applications, eds R. F. Baumeister and K. D. Vohs (New York, NY: Guilford Press), 229-248.

Eisenberg, N., Zhou, Q., Spinrad, T. L., Valiente, C., Fabes, R. A., and Lieu, J. (2005b). Relations among positive parenting, children's effortful control, and externalizing problems: a three-wave longitudinal study. Child Dev. 76, 1055-1071.

El-Sheikh, M. (2005). Does poor vagal tone exacerbate child maladjustment in the context of parental problem drinking? A longitudinal examination. J. Abnorm. Psychol. 114, 735-741.

Erath, S. A., El-Sheikh, M., Hinnant, J. B., and Cummings, E. M. (2011). Skin conductance level reactivity moderates the association between harsh parenting and growth in child externalizing behavior. Dev. Psychol. 47, 693-706.

Estelles, J., Rodríguez-Arias, M., Maldonado, C., Aguilar, M. A., and Miñarro, J. (2005). Prenatal cocaine exposure alters spontaneous and cocaine-induced motor and social behaviors. Neurotoxicol. Teratol. 27, 449-457.

Flavell, J. H. (1977). Cognitive Development. Englewood Cliffs, NJ: Prentice-Hall.

Gawin, F. H., and Ellinwood, E. H. (1988). Cocaine and other stimulants: actions, abuse, and treatment. N. Engl. J. Med. 318, 1173-1182.

Gendle, M. H., White, T. L., Strawderman, M., Mactutus, C. F., Booze, R. M., Levitsky, D. A., and Strupp, B. J. (2004). Enduring effects of prenatal cocaine exposure on selective attention and reactivity to errors: evidence from an animal model. Behav. Neurosci. 118, 290-297.

Goldsmith, H. H., and Rothbart, M. K. (1988). The Laboratory Temperament Assessment Battery (LAB-TAB). Anonymous, University of Oregon, Eugene, OR: Oregon Center for the Study (of) Emotion, Department of Psychology. [Technical Report 88-01].
Gottwald, S. R., and Thurman, S. K. (1994). The effects of prenatal cocaine exposure on mother-infant interaction and infant arousal in the newborn period. Topics Early Child. Spec. Educ. 14, 217-231.

Grossman, D. (1983). Repiration, stress, and cardiovascular function. Psychophysiology 20, 284-299.

Heyser, C. J., Molina, V. A., and Spear, L. P. (1992). A fostering study of the effects of prenatal cocaine exposure: I. Maternal behaviors. Neurotoxicol. Teratol. 14, 415-421.

Johns, J. M., Elliott, D. L., Hofler, V. E., Joyner, P. W., McMurray, M. S. Jarrett, T. M., Haslup, A. M., Middleton, C. L., Elliott, J. C., and Walker, C. H. (2005). Cocaine treatment and prenatal environment interact to disrupt intergenerational maternal behavior in rats. Behav. Neurosci. 119, 1605-1618.

Johns, J. M., McMurray, M. S., Hofler, V. E., Jarrett, T. M., Middleton, C. L., Elliott, D. L., Mirza, R., Haslup, A., Elliott, J. C., and Walker, C. H. (2007). Cocaine disrupts pupinduced maternal behavior in juvenile and adult rats. Neurotoxicol. Teratol. 29, 634-641.

Johns, J. M., Nelson, C., Meter, K. E., Lubin, D. A., Couch, C. D., Ayers, A., and Walker, C. H. (1998b). Dose-dependent effects of multiple acute cocaine injections on maternal behavior and aggression in Sprague-Dawley rats. Dev. Neurosci. $20,525-532$.

Johns, J. M., and Noonan, L. R. (1995). Prenatal cocaine exposure affects social behavior in SpragueDawley rates. Neurotoxicol. Teratol. $17,569-576$.

Johns, J. M., Noonan, L. R., Zimmerman, L. I., Li, L., and Pedersen, C. A. (1994). Effects of chronic and acute cocaine treatment on the onset of maternal behavior and aggression in Sprague-Dawley rats. Behav. Neurosci. 108, 107-112.

Johns, J. M., Noonan, L. R., Zimmerman, L. I., McMillen, B. A., Means, L. W., Walker, C. H., Lubin, D. A. Meter, K. E., Nelson, C. J., Pedersen, C. A., Mason, G. A., and Lauder, J. M. (1998a). Chronic cocaine treatment alters social/aggressive behavior in Sprague-Dawley rat dams and in their prenatally exposed offspring. Ann. N. Y. Acad. Sci. 846, 399-404.

Johnson, A. L., Morrow, C., Accornero, V. H., Xue, L., Anthony, B. C., and Bandstra, E. S. (2002). Maternal cocaine use: estimated effects on mother-child play interactions in the preschool period. J. Dev. Behav. Pediatr. 23, 191-202.

Karmel, B. Z., and Gardner, J. M. (1996) Prenatal cocaine exposure effects on arousal-modulated attention during the neonatal period. Dev. Psychobiol. 29, 463-480.

Keenan, K., and Shaw, D. S. (1994). The development of aggression in toddlers: a study of low-income families. J. Abnorm. Child. Psychol. 22, 53-78.

Kinsley, C. H., Turco, D., Bauer, A., Beverly, M., Wellman, J., and Graham, A. L. (1994). Cocaine alters the onset and maintenance of maternal behavior in lactating rats. Pharmacol. Biochem. Behav. 47, 857-864.

Kochanska, G., and Aksan, N. (1995). Mother-child mutually positive affect, the quality of child compliance to requests and prohibitions, and maternal control as correlates of early internalization. Child Dev. 66, 236-254.

Kochanska, G., Aksan, N., and Nichols, K. E. (2003). Maternal power assertion in discipline and moral discourse contexts: commonalities, differences, and implications for children's moral conduct and cognition. Dev. Psychol. 39, 949-963.

Kochanska, G., and Knaack, A. (2003) Effortful control as a personality characteristic of young children antecedents, correlates, and consequences. J. Pers. 71, 1087-1112.

Kochanska, G., Murray, K. T., and Coy, K. C. (1997). Inhibitory control as a contributor to conscience in childhood: from toddler to early school age. Child Dev. 68, 263-277.

Kochanska, G., Murray, K. T., Jacques, T. Y., Koenig, A. L., and Vandegeest, K. A. (1996a). Inhibitory control in young children and its role in emerging internalization. Child Dev. 67 490-507.

Kochanska, G., Padavich, D., and Koenig, A. L. (1996b). Children's narratives about hypothetical moral dilemmas and objective measures of their conscience: mutual relations and socialization antecedents. Child Dev. 67, 1420-1436.

Kopp, C. B. (1982). Antecedents of selfregulation: a developmental perspective. Dev. Psychol. 18, 199-214.

LaGasse, L. L., Messinger, D., Lester, B. M., Seifer, R., Tronick, E. Z. Bauer, C. R., Shankaran, S., Bada H. S., Wright, L. L., Smeriglio, V. L. Finnegan, L. P., Maza, P. L., and Liu, J. (2003). Prenatal drug exposure and maternal and infant feeding behaviour. Arch. Dis. Child. Fetal Neonatal Ed. 88, F391-F399.

Li, Y. Q., Wang, X. Y., Zhai, H. F., Zheng, Y. Q., Zhang, X. Y., Kosten, T., and Lu, L. (2008). Effects of early postnatal sibling deprivation on anxiety and vulnerability to cocaine in offspring rats. Psychopharmacology (Berl.) 199, 245-253.
Linares, T. J., Singer, L. T., Kirchner, H. L., Short, E. J., Min, M. O., Hussey, P., and Minnes, S. (2006). Mental health outcomes of cocaine exposed children at 6 years of age. J. Pediatr. Psychol. 3, 85-97.

Littman, A., and Parmelee, B. (1978). Medical correlation of infant development. Pediatrics 61, 470-474.

Lubin, D. A., Meter, K. E., Walker, C. H., and Johns, J. M. (2001). Dose-related effects of chronic gestational cocaine treatment on maternal aggression in rats on postpartum days 2,3 , and 5. Prog. Neuropsychopharmacol. Biol. Psychiatry 25, 1403-1420.

Maccoby, E. E., and Martin, J. A. (1983). "Socialization in the context of the family: parent-child interaction," in Handbook of Child Psychology: Socialization, Personality, and Social Development, ed. E. M. Hetherington (New York: Wiley), 1-101.

MacKinnon, D. P., Lockwood, C. M., and Williams, J. (2004). Confidence limits for the indirect effect: distribution of the product and resampling methods. Multivariate Behav. Res. 39, 99-128.

Magura, S., Freeman, R. C., Siddiqi, Q., and Lipton, D. S. (1992). The validity of hair analysis for detecting cocaine and heroin use among addicts. Int. J. Addict. 27, 51-69.

Marcovitch, S., Leigh, J., Calkins, S. D., Leerks, E. M., O’Brien, M., and Blankson, A. N. (2010). Moderate vagal withdrawal in 3.5-year-old children is associated with optima performance on executive function with optimal performance on executive function tasks. Dev. Psychobiol. 52, 603-608.

Mayes, L. C., Grillon, C., Granger, R. H., and Schottenfeld, R. (1998) "Regulation of arousal and attention in preschool children exposed to cocaine prenatally," in Cocaine: Effects on the Developing Brain, eds J. A. Harvey and B. E. Kosofsky (New York: New York Academy of Sciences), 126-143.

McMurray, M. S., Joyner, P. W., Middleton, C. W., Jarrett, T. M., Elliott, D. L., Black, M. A., Hofler, V. E., Walker, C. H., and Johns, J. M. (2008). Intergenerational effects of cocaine treatment and rearing environment on aggressive behavior and oxytocin in rats. Stress 11,398-410.

Mehta, S. K., Finkelhor, R. S., Anderson, R. L., Harcar-Sevik, R. A., Wasser, T. E., and Bahler, R. C. (1993). Transient myocardial ischemia in infants prenatally exposed to cocaine. $J$. Pediatr. 122, 945-949.

Mezzacappa, E., Kindlon, D., Saul, J. P., and Earls, F. (1998). Executive and motivational control of performance task behavior, and autonomic 
heart-rate regulation in children: physiologic validation of two-factor solution inhibitory control. J. Child Psychol. Psychiatry 39, 525-531.

Mieczkowski, T., and Newel, R. (1997). "Patterns of concordance between hair assays and urinalysis for cocaine: longitudinal analysis of probationers in Pinellas County, Florida," in The Validity of SelfReported Drug Use: Improving the Accuracy of Survey Estimates, eds L. Harrison and A. Hughes (Maryland: Department of Health and Human Services), 161-199.

Molitor, A., Mayes, L. C., and Ward, A. (2003). Emotion regulation behavior during a separation procedure in 18-month-old children of mothers using cocaine and other drugs. Dev. and Psychopathol. 15, 39-54.

Muthén, L. K., and Muthén, B. O. (1998-2004). Mplus User's Guide, 3rd Edn. Los Angeles, CA: Muthén and Muthén.

Nassogne, M. C., Evrard, P., and Courtoy, P. J. (1998). "Selective direct toxicity of cocaine on fetal mouse neurons. Teratogenic implications of neurite and apoptotic neuronal loss," in Cocaine: Effects on the Developing Brain, eds J. A. Harvey and B. E. Kosofsky (New York: New York Academy of Sciences), 51-68.

Nelson, C. J., Meter, K. E., Walker, C. H., Ayers, A. A., and Johns, J. M. (1998). A dose-response study of chronic cocaine on maternal behavior in rats. Neurotoxicol. Teratol. 20, 657-660.

Neugebauer, N. M., Cunningham, S. T., Zhu, J., Bryant, R. I., Middleton, L. S., and Dwoskin, L. P. (2004). Effects of environmental enrichment on behavior and dopamine transporter function in medial prefrontal cortex in adult rats prenatally treated with cocaine. Brain Res. Dev. Brain Res. 153, 213-223.

Newby, K., and Campbell, S. B. (1999). Self-regulation: both a child trait and a dyadic variable. Presented at Society for Research in Child Development, Albuquerque, NM.

Overstreet, D. H., Moy, S. S., Lubin, D. A., Gause, L. R., Lieberman, J. A., and Johns, J. M. (2000). Enduring effects of prenatal cocaine administration on emotional behavior in rats. Physiol. Behav. 70, 149-156.

Porges, S. W. (1991). "Vagal tone: an autonomic mediator of affect," in The Development of Emotion Regulation and Dysregulation. Cambridge Studies in Social and Emotional Development, eds J. Garber and K. A. Dodge (New York: Cambridge University Press), 111-128.
Porges, S. W. (1996). Physiological regulation in high-risk infants: a model for assessment and potential intervention. Dev. Psychopathol. 8, 43-58.

Porges, S. W. (2007). The polyvagal perspective. Biol. Psychol. 74, 116-143.

Porges, S. W., Doussard-Roosevelt, J. A., Portales, A. L., and Greenspan, S. I. (1996). Infant regulation of the vagal "brake" predicts child behavior problems: a psychobiological model of social behavior. Dev. Psychobiol. 29, 697-712.

Posner, M. I., and Rothbart, M. K. (2000). Developing mechanisms of self-regulation. Dev. Psychopathol. 12, 427-441.

Regalado, M. G., Schechtman, V. L., Del Angel, A. P., and Bean, X. D. (1996). Cardiac and respiratory patterns during sleep in cocaineexposed neonates. Early Hum. Dev. 44, 187-200

Regalado, M. G., Schechtman, V. L., Khoo, M. C. K., and Bean, X. D. (2001). Spectral analysis of heart rate variability and respiration during sleep in cocaine-exposed neonates. Clin. Physiol. 21, 428-436.

Richardson, G. A., Goldschmidt, L., and Willford, J. (2009). Continued effects of prenatal cocaine use: preschool development. Neurotoxicol. Teratol. 31, 325-333.

Robbins, T. W. (1997). Arousal systems and attentional processes. Biol. Psychol. 45, 57-71.

Rose-Jacobs, R., Waber, D., Beeghly, M., Cabral, H., Appugleise, D., Heeren, T., Marani, J., and Frank, D. A. (2009). Intrauterine cocaine exposure and executive functioning in middle childhood. Neurotoxicol. Teratol. 31, 159-168.

Rothbart, M. K., Derryberry, D., and Posner, M. (1994). "A psychobiological approach to the development of temperament," in Temperament: Individual Differences at the Interface of Biology and Behavior, eds J. E. Bates and T. D. Wachs (Washington, DC: American Psychological Association), 83-116.

Rothbart, M. K., Posner, M., and Boylan, A. (1990). "Regulatory mechanisms in infant development," in The Development of Attention: Research and Theory. Advances in Psychology, ed. J. T. Enns (Amsterdam: NorthHolland), 47-66.

Savitz, D. A., Henderson, L., Dole, N., Herring, A., Wilkins, D. G., Rollins, D., and Thorp, J. M. (2002). Indicators of cocaine exposure and preterm birth. Obstet. Gynecol. 99, 458-465.

Schuetze, P., and Eiden, R. D. (2006). The association between maternal cocaine use during pregnancy and physiological regulation in 4- to 8week-old infants: an examination of possible mediators and moderators. J. Pediatr. Psychol. 31, 15-26.

Schuetze, P., Eiden, R. D., and Danielewicz, S. (2009a). The association between prenatal cocaine exposure and physiological regulation at 13 months of age. J. Child Psychol. Psychiatry 50, 1401-1409.

Schuetze, P., Eiden, R. D., and Edwards, E. P. (2009b). A longitudinal examination of physiological regulation in cocaine-exposed infants across the first 7 months of life. Infancy 14, 19-43.

Sheinkopf, S. J., LaGasse, L. L., Lester, B. M., Liu, J., Seifer, R., Bauer, C. R., Shankaran, S., Bada, H., and Das, A. (2007). Vagal tone as a resilience factor in children with prenatal cocaine exposure. Dev. Psychopathol. 19, 649-673.

Silvestri, J. M., Long, J. M., Weese-Mayer, D. E., and Barkov, G. A. (1991). Effect of prenatal cocaine on respiration, heart rate, and sudden infant death syndrome. Pediatr. Pulmonol. 11, 328-334.

Sobell, M. B., Sobell, L. C., Klajmer, F., Pavan, D., and Basian, E. (1986). The reliability of a timeline method for assessing normal drinker college students' recent drinking history. Addict. Behav. 11, 149-162.

Sobrian, S. K., Burton, L. E., Robinson, N. L. Ashe, W. K., James, H., Stokes, D. L., and Turner, L. M. (1990). Neurobehavioral and immunological effects of prenatal cocaine exposure in rats. Pharmacol. Biochem. Behav. 35, 617-629.

Spear, L. P., Campbell, J., Snyder, K., Silveri, M. M., and Katovic, N. M. (1998). "Animal behavior models: increased sensitivity to stressors and other environmental experiences after prenatal cocaine exposure," in Cocaine: Effects on the Developing Brain, eds J. A. Harvey and B. E. Kosofsky (New York: New York Academy of Sciences), 76-88.

Stifter, C. A., and Braungart, J. M. (1995). The regulation of negative reactivity in infancy: function and development. Dev. Psychol. 31, 448-455.

Tucker, D. M., and Williamson, P. A. (1984). Asymmetric neural control systems in human self-regulation. Psychol. Rev. 91, 185-215.

Vernotica, E. M., Lisciotto, C. A., Rosenblatt, J. S., and Morrell, J. I. (1996). Cocaine transiently impairs maternal behavior in the rat. Behav. Neurosci. 110, 315-323.
Vernotica, E. M., Rosenblatt, J. S., and Morrell, J. I. (1999). Microinfusion of cocaine into the medial preoptic area or nucleus accumbens transiently impairs maternal behavior in the rat. Behav. Neurosci. 113, 377-390.

Warner, T. D., Behnke, M., Hou, W., Garvan, C. W., Wobie, K. and Eyler, F. D. (2006). Predicting caregiver-reported behavior problems in cocaine-exposed children at 3 years. J. Dev. Behav. Pediatr. 27, 83-92.

Wood, R. D., Bannoura, M. D., and Johanson, I. B. (1994). Prenatal cocaine exposure: effects on play behavior in the juvenile rat. Neurotoxicol. Teratol. 16, 139-144.

Wood, R. D., Molina, V. A., Wagner, J. M., and Spear, L. P. (1995). Play behavior and stress responsivity in periadolescent offspring exposed prenatally to cocaine. Pharmacol. Biochem. Behav. 52, 367-374.

Wood, R. D., and Spear, L. P. (1998). Prenatal cocaine alters social competition of infant, adolescent, and adult rats. Behav. Neurosci. 112, 419-431.

Yumoto, C., Jacobson, S. W., and Jacobson, J. L. (2008). Fetal substance exposure and cumulative environmental risk in an African American cohort. Child Dev. 79, 1761-1776

Zimmerberg, B., and Gray, M. S. (1992). The effects of cocaine on maternal behaviors in the rat. Physiol. Behav. 52, 379-384.

Conflict of Interest Statement: The authors declare that the research was conducted in the absence of any commercial or financial relationships that could be construed as a potential conflict of interest.

Received: 15 February 2011; paper pending published: 25 April 2011; accepted: 17 May 2011; published online: 31 May 2011.

Citation: Eiden RD, Schuetze P, Veira $Y$, Cox E, Jarrett TM and Johns JM (2011) Cocaine exposure and children's self-regulation: indirect association via maternal harshness. Front. Psychiatry 2:31. doi: 10.3389/fpsyt.2011.00031 This article was submitted to Frontiers in Child and Neurodevelopmental Psychiatry, a specialty of Frontiers in Psychiatry. Copyright (C) 2011 Eiden, Schuetze, Veira, Cox, Jarrett and Johns. This is an openaccess article subject to a non-exclusive license between the authors and Frontiers Media SA, which permits use, distribution and reproduction in other forums, provided the original authors and source are credited and other Frontiers conditions are complied with. 